\title{
EL ACOSO COMO PARTE DE LA VIOLENCIA DE GÉNERO
}

\section{Lic. Nancy del Carmen De la O Frías ${ }^{1}$ \\ Dr. José Antonio Morales Notario ${ }^{2}$}

\begin{abstract}
The cultural models born of patriarchy and machismo continue to be rooted in Mexican society. Discrimination against women is the result of years of male domination.

internet as a media has developed quickly and today, it has become a means of generating harassment against women without there being a way to prevent it because the law is lagging behind.
\end{abstract} Mexican statistics indicate that almost $40 \%$ of men think that women should work in activities specific to their sex and one in three consider it normal men earn more than women. Therefore, the violence as a manifestation of the abuse of power damage the self-esteem, health, integrity, freedom and security of women. Impunity generates unlawful behaviors such as workplace harassment, which can be sexual and to seek to affect human dignity. Behaviors such as unwanted compliments, the morbid looks, suggestive gesture, teasing, jokes or comments with sexual content should be cast because in many cases it is intended that the person accepts invitations to unwanted encounters or that puts her integrity in risk. The

Keywords: Women, gender, internet, harassment

\section{Introducción.}

En la actualidad, las redes sociales han tenido un auge vertiginoso y se han convertido en un excelente medio, no sólo de comunicación sino también de denuncia. A través de ella surgen a la luz conductas que anteriormente permanecían en el olvido como lo es el acoso. Sin embargo, las nuevas tecnologías también permiten el anonimato detrás de una pantalla y por ello no existe responsabilidad en el uso de los medios de comunicación electrónicos. En consecuencia, generalmente se tienden a confundir

\footnotetext{
${ }^{1}$ Licenciada en Derecho por parte de la Universidad Juárez Autónoma de Tabasco y Egresada de la Maestría en Derecho de la División Académica de Ciencias Sociales y Humanidades de la Universidad Juárez Autónoma de Tabasco.

${ }^{2}$ Doctor en Derecho y Profesor Investigador de tiempo completo en la Universidad Juárez Autónoma de Tabasco.
} 
acciones considerando que todas tienen una finalidad basada en el género

Es cierto que las mujeres mantienen una lucha constante por el reconocimiento de sus derechos; mientras que, en esta sociedad marcada por la misoginia y el machismo, el hombre ha realizado algunas concesiones con la finalidad de calmar al género femenino, por lo menos momentáneamente en sus reclamos, pero sin modificar las conductas que durante décadas y centurias han causado un daño enorme a las mujeres, tanto en su persona como en su dignidad.

En México, la igualdad de género que se reclama a través de los diversos foros existentes ha experimentado numerosos cambios, no sólo en el ámbito social sino también en el profesional, laboral, educativo $\mathrm{y}$ político, entre otros. Las mujeres que han sostenido esta lucha, han redoblado su participación con el objetivo de reducir la brecha de desigualdad, violencia, discriminación y diferenciación sexual.

De acuerdo al Consejo Nacional de Población (CONAPO, 2010), en el 2009 habían 54.7 millones de mujeres mexicanas, lo que representaba el 50.9\% de los 107.6 millones de habitantes del
82

país. Sin embargo, aún se está lejos de alcanzar un verdadero equilibrio de género porque a pesar de ser mayoría, se encuentran relegadas en una sociedad que se basa en principios machistas y patriarcales.

En ese aspecto, la igualdad, que está establecida en diversos instrumentos, tanto nacionales como internacionales, fija las bases fundamentales para exigir y lograr el equilibrio entre hombres y mujeres en la realidad; pero, a pesar de que las diferentes legislaciones se constituyen en un referente para la creación de políticas públicas y para el cumplimiento de las leyes, las mujeres sufren de violencia basada en su género.

La discriminación y el rechazo hacia lo femenino provoca el clima de violencia que sufren y es un fenómeno que remarca los patrones culturales contenidos en las costumbres y las tradiciones. El problema radica en que aún se sigue confundiendo al género con el sexo. El primero apunta a características fisiológicas y sexuales con las que nacen tanto los hombres como las mujeres; mientras que el género representa las ideas, normas y comportamientos que la sociedad ha 
establecido para cada sexo, sea hombre o mujer, otorgándoles un valor $\mathrm{y}$ significado (UNICEF, S.F.).

La Organización Mundial de la Salud (2019) ha indicado que el género se asocia a conceptos sociales como funciones, comportamientos, actividades y atributos que la sociedad le otorga a hombres y mujeres basados en las diferencias fisiológicas y sexuales entre éstos. Mientras que el sexo es determinado por la naturaleza, el género se aprende; es una construcción social que define las diferentes características emocionales, afectivas, intelectuales y comportamientos asignados como propios y naturales a cada rol.

Empero, la diferencia no debe ser considerada sólo como un aspecto anatómico, sino como símbolo de identidad sexual. El sexo y el género no se relacionan entre sí como lo hace la naturaleza y la cultura, porque la sexualidad es construida de manera cultural mientras que el género es asignado desde el momento en que un niño o niña nace y se asocia su identidad a sus genitales. El cuerpo, a partir de ese momento, tendrá un significado que lo diferenciará de los demás y que construirá su masculinidad $\mathrm{o} \quad \mathrm{su}$ feminidad dependiendo del caso (CAZÉS, 1999).

La sociedad funda las actividades de cada ser humano de acuerdo a su sexualidad y constituye un coto de poder de uno sobre el otro. Las relaciones entre el hombre y la mujer, históricamente han sido desequilibradas: desde el inicio de la humanidad se dividió el trabajo, se construyó un consenso social entre ciudadanos y ciudadanas de manera subjetiva y se estableció la normatividad sexual incluyendo los roles que cada género debería de desempeñar, pero privilegiando al patriarcado que se estructuró alrededor del hombre de manera paradigmática.

Al ser el varón el que contaba con el poder de decisión, su ejercicio creó una desigualdad social que dio origen al sexismo como forma de exclusividad, generando con esto la discriminación hacia todo lo femenino, oprimiéndola y reduciéndola a su mínima expresión.

\section{La violencia hacia el género: una construcción social.}

En ese sentido, esa diferencia de funciones físicas, dio como resultado la 
violencia cotidiana hacia las niñas y mujeres del mundo que se refleja a través de conductas que laceran y causan daños en aspectos como el físico, el psicológico, el patrimonial, el económico y el sexual.

La Declaración de las Naciones Unidas sobre la Eliminación de la Violencia contra la Mujer (OHCHR, 1993) ha señalado que cuando se busca causar un daño o sufrimiento a una mujer en su humanidad, ya sea de manera física o mental, en sus bienes, en sus finanzas $y$ en el plano sexual por el hecho de pertenecer al género femenino, así como cuando exista la amenaza de realizar tales actos, la coacción o la privación arbitraria de la libertad, se constituye un acto de violencia hacia ella, sin importar si es en la vida pública o privada.

En dicha declaración también se reconoce que la violencia contra la mujer en cualquier ámbito de la vida, se ha generalizado y trasciende las diferencias de ingresos; las clases sociales, pues no es privativa de una sola y la cultura; por ello deben crearse medidas urgentes y eficaces que la contrarresten pues la sociedad en general, ante la vulnerabilidad que ha mostrado el género femenino.
84

No se puede dejar de observar que la violencia se asocia a lo impetuoso, a lo colérico, a la ira, al fracaso derivado de las acciones de personas o grupos que tienen cierto coto de poder sobre los demás. Es la ruptura de un orden establecido y de una armonía preexistente y lo opuesto a lo que genera la paz. En la actualidad, la violencia puede ser generada por diversas razones, desde cuestiones que tienen que ver con comportamientos $\quad$ o deseos desmesurados que están presente en nuestra vida privada y colectiva, de manera cotidiana hasta cuestiones simples como diferencias entre las personas. Sin embargo, se debe de partir de la idea que la violencia se aprende a lo largo de la vida y por ello no puede ser considerada innata; es evitable y se puede combatir en sus causas (JIMÉNEZ-BAUTISTA, 2012).

En el manifiesto de Sevilla (1989), la violencia se considera la representación del ejercicio del poder, ya que a través de ella se justifican las guerras y se legitima cualquier tipo de discriminación basada en el sexo, la raza o la clase social. El ser humano es propenso a provocar conflictos toda vez que es producto de su cultura, ya que a 
través de la violencia se justifica un comportamiento agresivo en perjuicio de todo tipo de conducta más dirigidos a la paz. En la actualidad, los Estados tienen el reto de reducir el clima de violencia que se vive en el mundo.

Las teorías en torno a la desigualdad entre hombres y mujeres intentan explicar este desequilibrio social. Desde siempre la mujer ha sido vista como un ser débil, inferior al hombre al que debe de servir, con diligencia, respeto, de manera sumisa. Ejemplo de lo anterior hay cientos en la literatura tanto nacional como internacional y de diversos géneros.

Dentro de la tradición judíocristiana se tiene la historia de Eva, creada a partir de las costillas de Adán; mientras que Lilit, que fue la primera mujer en el Paraíso, fue expulsada por no obedecer a su pareja y exigir la igualdad frente a él. Eva es la imagen de la voluptuosidad ya que su cuerpo es la manifestación más clara del deseo y del placer, pero también simboliza la curiosidad hacia lo no permitido y el peligro de la desobediencia del poder; representa el pecado y el saber, sin embargo, está subyugada por Adán y por su desobediencia a Dios al comer de la manzana del bien y del mal que trajo como resultado el pecado original al mundo (MAGAÑA, 2014).

Ante ello, es claro que la iglesia ha jugado un papel decisivo en la construcción de los roles de género. Por un lado, Eva representa el pecado, la curiosidad, el castigo a las mujeres por haber desobedecido a Dios $\mathrm{y}$, en consecuencia, están subyugadas a la decisión del marido. En cambio, en la escena también aparece María que significa la construcción de un nuevo paradigma: es la virginidad, la castidad y la abnegación como esposa y como madre, con características asignadas a las mujeres: casta, prudente, trabajadora, honrada, callada, obediente, hermosa y culta; dedicada al cuidado y educación de los hijos y a la organización de la economía familiar (DUARTE \& BALTAZAR, 2016).

A partir de esto se construye la identidad de la mujer y se justifica el maltrato. Sin embargo, este no es el único ejemplo. En la antigüedad, la mujer permanecía ajena a toda clase de educación formal y en su gran mayoría eran analfabetas. Aquellas que pertenecían a la nobleza, podían recibir la misma educación que los hombres, 
pero tenían prohibido enseñar. Esta última previsión se basaba precisamente en la creencia de que: la mujer no era inteligente en igual medida que el hombre; la sujeción a la que estaban sometidas; la asociación de su apariencia con la lujuria y, el recuerdo de la primera mujer que enseñó sólo una vez y que puso al mundo de cabeza (REHERMANN, 2016).

En ese mismo tenor, la mitología griega también construye una identidad hacia la mujer. Hera, esposa de Zeus, es la diosa del matrimonio, símbolo e institución sagrada de las relaciones de poder entre hombres $\mathrm{y}$ mujeres y responsable de la salvaguarda de éste. Dentro de sus atributos, representa un orden simbólico patriarcal: estaba sujeta a la obediencia y al hecho del "ser de", con lo que se justificó la dependencia vital hacia el esposo, persona clave en el contrato matrimonial celebrado entre ambos: mujer y hombre y con el que sellaban su unión. De igual forma, dentro de la leyenda, se encuentran elementos de dominación hacia ella. Zeus la violó y ante ello asumió que los hombres, a través del sistema patriarcal implantado, son responsables de los abusos y violaciones.
$\mathrm{Su}$ mayor humillación consistió en casarse con su violador con la finalidad de restituir la pérdida de su virginidad; con ello, se crea una relación de dependencia entre ambos géneros. Asimismo, se personificaba a Hera como una mujer celosa, iracunda, enfadada, colérica y vengativa, ante un hombre con actitudes promiscuas. La primera actitud reprobada por la sociedad y rechazada como propia de las mujeres, mientras que la segunda es tolerada por una sociedad que, a través de la debilidad de los dioses muestran su organización social y política (ALZARD, 2013).

De esta forma, desde la antigüedad se construye el paradigma de la mujer, al asociarse los grandes males del mundo con su existencia. Ella representa lo negativo, mientras que para el hombre todo está permitido.

Sin embargo, la desigualdad existente entre hombres y mujeres, en 1975, en la Primera Conferencia Mundial de la Mujer en México, se habló de discriminación, salud y desarrollo económico; lo que visibilizó la condición real de la mujer que vive con discriminación, opresión, subordinación, segregación y maltrato; lo que puso en evidencia la necesidad de sumar a los 
procesos de desarrollo y democráticos de los países a las mujeres y de equilibrar los roles existentes (DUARTE \& BALTAZAR, 2016).

\section{La violencia de género. Un reto para los derechos humanos.}

$\mathrm{Si}$ bien es cierto que, en la Constitución Política de los Estados Unidos Mexicanos (DIPUTADOS, 2019) se establece en el artículo 4 la igualdad de género entre hombre y mujer sin tomar en cuenta sus diferencias, no escapa de la observación que la situación entre ambos no ha cambiado. Siguen existiendo brechas entre cada uno y se sigue considerando al género femenino como acompañante y objeto sexual, cuyo principal papel es la reproducción, mientras que los varones mantienen una jerarquía mayor dentro del plano biológico y social.

La Organización Mundial de la Salud (OMS, 2013) ha señalado que la violencia de género es un problema de salud pública, por lo que se requiere la intervención conjunta en todos los ámbitos; principalmente porque el 35\% de mujeres del mundo han sido víctimas de violencia física o sexual por parte de su pareja o de violencia sexual por parte de personas distintas de su pareja. El 30 $\%$ de las mujeres que han mantenido una relación de pareja, han sufrido de violencia física y/o sexual y a nivel mundial, el $38 \%$ de los homicidios femeninos son por violencia conyugal. Sin embargo, debe de considerarse que el número puede ser mayor, tomando en consideración que la mayor parte de las víctimas no se atreve a denunciar ante la posibilidad de ser revictimizadas por la autoridad.

Sin embargo, la labor aún está lejos de concluir, principalmente porque en México se implantaron modelos culturales, fundamentados en el patriarcado y en el machismo; lo que ha dado lugar a la violación de los derechos humanos de la mujer. Es imprescindible visualizar la problemática de la violencia de género desde una perspectiva que ofrezca cambios reales y posibles, considerando su impacto y carácter.

Las discriminaciones que sufre la mujer son producto de su condición física y se manifiesta a través de la dominación que los varones ejercen sobre ella desde el momento de su nacimiento, durante el transcurso de su infancia y juventud y en el tiempo de su 
vejez. El control social está basado en el poder de los varones que permite la subordinación de las mujeres y, en consecuencia, las violaciones a los derechos humanos de las mujeres están vinculadas de manera directa o indirecta con el género y los valores culturales.

La Convención Interamericana para Prevenir y Sancionar y Erradicar la Violencia contra la Mujer (Belem Do Pará) y la Convención sobre la eliminación de todas las formas de discriminación contra las mujeres (CEDAW) son instrumentos jurídicos en los que se reconoce que la violencia y la discriminación limitan el reconocimiento, goce y ejercicio de los derechos y libertades de las mujeres. Por ello, la violencia hacia la mujer representa la práctica más común del ejercicio desigual del poder entre las mujeres y los hombres. Empero, es difícil erradicar conductas que están arraigadas en prácticas con profundo arraigo cultural, ya que la violencia es ejercida tanto en el contexto familiar como el doméstico.

En la Primera Encuesta Nacional sobre Discriminación en México (ENADI) (CENEPRED, 2005), se puntualizó que la discriminación se percibe más en los homosexuales y discapacitados, siendo las mujeres colocadas en tercera posición por encima de los indígenas, adultos mayores $\mathrm{y}$ minorías religiosas. Por ello, el fenómeno es invisibilizado pues ellas consideran que no sufren de discriminación o bien, no le prestan la atención adecuada. A la pregunta de si habían sufrido un acto de discriminación por su condición; en primer lugar, se ubicó a las personas con diferencias sexuales diversas, seguido de los discapacitados, los indígenas, los adultos mayores, las minorías indígenas y en último lugar se ubicó a las mujeres. En ese mismo sentido, el mexicano promedio considera que no da un trato discriminatorio a las mujeres. El $84 \%$ aparentemente respeta que alguien decida ser madre soltera; casi el $90 \%$ opina que el negarle el empleo a una mujer embarazada es una violación a sus derechos humanos. El 83\% está dispuesto a pagar incapacidades por embarazo para que se respete el derecho al trabajo de las mujeres. Casi el 100\% afirma que no se justifica que un hombre le pegue a una mujer.

Sin embargo, todavía existe una cultura machista y de discriminación en 
el mexicano promedio. Uno de cada cinco varones considera que es natural que a las mujeres se les prohíban más cosas que a los hombres; casi el 15 por ciento opina que no se debía gastar tanto en la educación de las hijas porque luego se casan: y uno de cada cuatro le pediría un examen de embarazo a una mujer al solicitar un empleo. Casi el $40 \%$, piensa que las mujeres que quieren trabajar deben hacerlo en tareas propias de su sexo y casi uno de cada tres opina que es normal que los hombres ganen más que las mujeres. El $21 \%$ opina que las mujeres tienen menos capacidad que los hombres para ejercer cargos importantes y uno de cada cuatro está de acuerdo en que las mujeres son violadas porque provocan a los hombres (CENEPRED, 2005).

Lo anterior sólo refuerza las ideas y pensamientos de una sociedad que aún no ha logrado despojarse de los patrones culturales existentes. $\mathrm{La}$ discriminación hacia la mujer persiste a pesar de las obligaciones positivas que se plasmaron en la ley. Se utilizan los prejuicios de manera deliberada $\mathrm{o}$ inconsciente: por un lado, es deber proteger a las mujeres, sin embargo, enfrentan situaciones que les impiden participar en igualdad de circunstancias en todos los ámbitos de la vida (LAMAS, 1996).

Esta discriminación de la que es objeto la mujer, es parte de una realidad que vulnera el principio de equidad y el respeto a su dignidad humana. Su lucha ha sido lenta, pero ha logrado con el paso del tiempo que se le reconozcan derechos; y cuando los tribunales nacionales no han sido capaces de restituirle en el goce de sus garantías violadas, los tribunales internaciones han estado presto atención y han intervenido de manera pronta.

El primer caso de violencia de género que se llevó ante la Corte Interamericana fue el de "González y otras (Campo Algodonero) (2009), y se concluyó que muchos de los homicidios perpetrados en Ciudad Juárez ocurrían en un contexto de discriminación sistemática contra la mujer, la cual sólo podía entenderse por la desigualdad arraigada en la sociedad y que tiene sus raíces en la inferioridad y subordinación de las mujeres. $\mathrm{Al}$ romperse este esquema planteado por los hombres con la incorporación de las mujeres a las fuerzas de trabajo y obteniendo de esta forma su independencia económica y 
nuevas oportunidades de formarse, surge la imagen de la mujer competitiva, que no fue acompañado de un cambio de actitudes y mentalidades tradicionales; es decir, se mantiene una visión estereotipada de los papeles sociales de hombre y mujer.

En consecuencia, la desigualdad que da como resultado la discriminación, es un factor de importancia y trascendencia ya que de ésta derivan conductas constitutivas de delitos. De 2012 a 2016, en el Estado de Tabasco hubo 1,745 víctimas de delitos sexuales. Con respecto a la edad, 496 eran niñas de 14 años o menos; 242, entre los 15 y los 17 años; 321 eran mayores de 18 y menores de 29; 170 tenían entre 30 y 39 años; 67 entre 40 y 49; 37 eran mayores de 50 años y 412 no contaban con registro; siendo el delito de violación el más común $(1,012)$; seguido de Pederastia (336), hostigamiento sexual (207); estupro (155), violación tumultuaria (21); violación equiparada (10); hostigamiento sexual agravado (3) y violación impropia (1) (CONAVIM, 2016).

La Ley General de Acceso de las Mujeres a una Vida Libre de Violencia (DOF, 2007) señala que existe
90

la violencia psicológica, la física, la patrimonial, la económica, la sexual y cualquier otra forma análoga que lesione o sea susceptible de dañar la integridad o libertad de las mujeres. Dentro de estas categorías, también están las modalidades: se puede dar en el ámbito familiar, en el ámbito laboral y docente, en la comunidad y por parte de las instituciones.

En el caso de la violencia que se ejerce en el ámbito laboral y docente, es considerada un acto u omisión relacionado con el abuso de poder que daña la autoestima, salud, integridad, libertad y seguridad de la víctima, e impide su desarrollo y atenta contra la igualdad. Tanto en el campo laboral como en el docente, el principal denominador es la subordinación de la víctima frente a su agresor y si la conducta verbal y/o físicas se relaciona con la sexualidad con un fin lascivo, entonces se está frente a un acoso sexual.

\section{El acoso como medio para violentar} los derechos de las mujeres.

El acoso no es una conducta nueva pero sí actual. Ha existido desde siempre. La Real Académica Española (2019) ha definido la acción de acosar 
como perseguir sin dar tregua o reposo a un animal o a una persona; o bien, apremiar de forma insistente a alguien con molestias o requerimientos. En otras palabras, el acoso está relacionado con una conducta insistente que da la sensación de persecución y que en ocasiones se asocia al hostigamiento que es la acción asociada a la incitación hecha hacia una persona para que haga algo.

En la mayoría de los casos, el acoso en general, tiene como signo característico que se trata de un ataque repetitivo, sistemático e intencional. Quien realiza el acoso busca abusar del otro y lo hace con la finalidad de dañarlo, exhibirlo, exponerlo a acciones negativas durante un tiempo, o bien, busca la burla o el escarnio público (CASTILLO-PULIDO, 2011). Cuando este hostigamiento se realiza con fines lascivos o sexuales, lo que busca es reprimir la libertad sexual de la mujer, que debe ser vista desde dos ángulos: a) el derecho que tiene al libre ejercicio de su sexualidad; y b) su derecho a que no se le imponga un contacto sexual que no desee.

Lo anterior no significa que el hombre no sufra de acoso laboral o
91

sexual, pero en la mayoría de los casos, se tiende a minimizar los efectos $\mathrm{y}$ reducir las consecuencias; principalmente porque culturalmente no es considerado un ser desprotegido; en cambio, los daños del acoso se resienten más si se trata de un grupo vulnerable, como lo son los niños, las niñas, las y los adolescentes, las mujeres, entre otros.

Como ya se ha señalado, existen diversos tipos de acoso, dependiendo del ámbito, la finalidad y las personas que lo realicen; por ello, se agrupa en acoso laboral, escolar y sexual.

El acoso laboral o mobbing es definido por la Organización Internacional del Trabajo (CNDH, 2017) como la acción verbal o psicológica de índole sistemática, repetida o persistente por la que, en el lugar de trabajo o en conexión con el trabajo, una persona o un grupo de personas hiere a una víctima, la humilla, ofende o amedrenta. El hostigamiento laboral tiene dos elementos: a) es vertical descendiente cuando ocurre por un superior jerárquico de la víctima, aunque también puede ser horizontal cuando se realiza entre compañeros de igual jerarquía ocupacional; y, b) se expresa en conductas verbales, física o ambas. 
Se considera bullying o acoso escolar a todo acto u omisión que agreda en lo físico, psicoemocional, patrimonial o sexual a una niña, niño o adolescente, realizado en alguna institución escolar pública o privada. Este tipo de conducta tiene como característica que coloca a las personas que lo padecen en una situación de vulnerabilidad respecto de quienes generan las agresiones, lo que les impide defenderse por sí solos. Hay un victimario $\mathrm{y}$ una víctima $\mathrm{y}$ es consecuencia de conductas externas a la escuela que les afectan (CNDH, 2018).

$$
\text { Cuando existe algún }
$$

comportamiento de naturaleza sexual que tenga el propósito o produzca el efecto de atentar contra la dignidad de una persona; principalmente al crearse un entorno laboral intimidatorio, degradante $\mathrm{u}$ ofensivo, es considerado acoso sexual (OIT, 2014).

El Protocolo para la Prevención, Atención y Sanción del Hostigamiento Sexual y Acoso Sexual en México (DOF, 2016) lo considera una forma de violencia que conlleva un ejercicio abusivo de poder, aunque no exista la subordinación con la víctima; pues se coloca a ésta en un estado de indefensión y de riesgo. Tanto el

\section{2}

hostigamiento como el acoso de índole sexual constituyen faltas de respeto, diligencia y rectitud hacia las personas con las que se tiene una relación con motivo del empleo. A través de estas conductas lesivas y dañinas, se atenta contra los valores éticos, los derechos humanos y la integridad física o psicológica de las víctimas, constituyendo una infracción que da lugar a un procedimiento y a una sanción, en el ámbito penal y en el administrativo.

El acoso laboral puede ser de tipo sexual, principalmente si se trata de acciones sexuales no recíprocas, como aquellas conductas verbales y físicas que traen consigo aspectos relacionadas con la sexualidad y son recibidas de tal forma que afectan la dignidad de la persona. También puede existir cuando exista una coerción sexual; es decir, que se presione a alguien para forzar su voluntad o su conducta sexual; cuando surjan sentimientos de desagrado para quien recibe la humillación, la insatisfacción personal, la molestia u opresión. Ejemplo de estas conductas están en los piropos no deseados que en muchas de las ocasiones tienen que ver con la apariencia física de una persona; las 
miradas morbosas o gestos sugestivos que incomodan a quien van dirigidos, las burlas, bromas o comentarios que tengan cierto contenido sexual; las cartas, llamadas telefónicas, correos electrónicos o mensajes de naturaleza sexual; la presión que se ejerce sobre una persona con la finalidad de que acepte invitaciones a encuentros o citas no deseadas fuera del trabajo, de manera insistente; ya sea de una persona al mismo nivel o de un superior jerárquico, el cual puede amenazar a la víctima que si no acepta, su situación laboral se puede agravar o incidir negativamente en su trabajo; el contacto físico no deseado y el intento de violación (STPS, S. F.).

Es importante aclarar que la diferencia entre acoso y hostigamiento sexual es muy sutil; a pesar de que ambas conductas tienden a considerarse sinónimos: el acoso se suscita en las escuelas, las familias, el transporte público o en el trabajo. Se da entre personas de igual jerarquía o que se encuentran al mismo nivel o por parte de alguien que ocupa una posición inferior a la persona que se acosa. En el caso del hostigamiento sexual, éste se ejerce de manera vertical; es decir, un superior jerárquico que utiliza su posición o cargo
93

para obtener alguna satisfacción, a través de amenazas u ofrecimientos relacionados con la situación laboral o educativa de la persona subalterna (DOF, 2007).

En el acoso u hostigamiento, como se ha señalado, no siempre tendrá la finalidad de ser sexual. El comportamiento que despliega el agresor es parte importante y clave para entender el fenómeno, pues el fin mismo consiste en un hacer de tipo sexual; sin embargo, no hay que confundirlo con el coqueteo, que es utilizado en múltiples ocasiones como justificación para desconocer conductas que son constitutivas del delito de acoso y hostigamiento.

A través del coqueteo, las personas hacen patente su deseo o interés sexual o emocional hacia otra. Las miradas, mensajes corporales, verbales o insinuaciones, le hacen saber al receptor el interés que despierta en la otra o la atracción que siente el emisor. Se da en la calle, en el cine, la escuela, el supermercado, el trabajo y en la actualidad, en los teléfonos celulares. Su característica principal es que es mutuamente aceptado por ambas partes y es muchas veces el preludio de un encuentro sexual ocasional o de una 
relación de pareja, o bien, puede no darse el contacto. Cuando no es recíproco, las acciones se tornan pesadas, agobiantes, cansadas, intimidantes e incluso indeseables para quien las recibe ya que no es su deseo entablar una relación con quien le envía el mensaje, y esto puede ser el inicio de acciones que deriven en hostigamiento o acoso sexual (UACJ, S.F.).

El problema se agudiza todavía más porque existe la creencia generalizada de que la mujer "es coqueta", "viste de forma sugerente o voluptuosa", "es seductora", "se comporta de tal o cual manera", "asume actitudes de invitación para que tengan contacto sexual con ella", etc.; ellas son responsables de provocar el deseo sexual, natural e incontenible en los hombres. No obstante, esta actitud masculina lo único que refleja es la costumbre arraigada del hombre de responsabilizar a la mujer por la exhibición de su cuerpo o por usar sus coqueteos para provocar, por ello, las víctimas son responsables y no los agresores, pues éstos sólo respondieron a los estímulos que recibieron.

Esto debido a la construcción social que permite que los hombres no conciban el acoso y el hostigamiento sexual de la misma manera que las mujeres. Se minimizan los sentimientos hostiles e intimidatorios, la humillación y el abuso de poder que sufren ellas. Además, los comentarios e insinuaciones sexuales no son deseados, o se realizan acciones para comercializar o utilizar de cualquier modo la sexualidad de las personas mediante el uso de la fuerza o la coacción para obtener un beneficio de índole sexual. El acoso u hostigamiento es percibido como un acto de molestia y hostilidad, que tiene un patrón recurrente y que provocan miedo, inseguridad, enojo, impotencia, tristeza, impunidad y molestia (AGUILAR, ARRIAGA, \& ET AL, 2017).

Por ello, no es fácil detectar los casos de acoso y hostigamiento, porque constituyen prácticas cotidianas que en la mayor parte de las ocasiones están cargadas de afectos, emociones y prejuicios de género que se mezclan con nuestras actitudes y percepciones; lo que dificulta el dimensionar y atacar el problema.

\section{Las redes sociales, el hostigamiento y el acoso sexual.}


El internet es un medio abierto a la población de todas las edades, debido a la adaptabilidad, su facilidad y sencillez. Sin embargo, no es sino con el uso de las redes sociales, que el fenómeno del acoso y del hostigamiento sexual se ha agudizado. A través de mensajes de texto, redes sociales, correos electrónicos, páginas web, blogs, salas de chat y aplicaciones como whatsapp, Messenger y Facebook, entre otras, se comparte información en textos, fotografías, imágenes modificadas $\mathrm{o}$ editadas; todo con el uso de una computadora o teléfono celular (MENDOZA, 2012) lo que permite todavía una interacción mayor entre las personas, que comparten información privada y la vuelven pública, lo que los hace vulnerables: muestran su intimidad, sentimientos, fracasos, gustos, acontecimientos personales, los lugares que visita, la comida que prefiere, lo que le molesta. Esto desafortunadamente permite el contacto, en muchas veces indeseable de otros usuarios o bien, realizan conductas que pueden constituir un delito.

En una encuesta realizada en el 2017, los resultados arrojaron que, de 70 millones de mexicanos conectados a
95

internet, 66.5 millones de internautas (95\%) usaban Facebook, seguido de Youtube (72\%), Twitter (66\%), Instagram (59\%) y Snapchat (31\%). Whatsapp es utilizado por 65.1 millones de usuarios (93\%). Linkedin cuenta con un $56 \%$ y Tinder, la cual es una red social de tipo amoroso, cuenta con 5.6 millones de seguidores (8\%) (EXCELSIOR, 2017).

A través de las redes sociales, las personas interactúan por variadas razones; sin embargo, lo que alienta su uso es la necesidad de estar comunicado, actualizado e informado. Esto trae como consecuencia una adicción hacia las redes, todo por el sólo hecho de estar en contacto con otras personas, que, quizás en el mundo real nunca conocerían, pero que, en el universo cibernético tienen puntos de afinidad y contacto (EL ORIENTE, 2014).

En la actualidad, las redes sociales se organizan en categorías relacionadas con aspectos de la vida cotidiana, como lo es el trabajo, la escuela, los grupos religiosos, el ocio $\mathrm{u}$ otro interés que pudiera tener un usuario. Facebook muestra el número de amigas y amigos, limitando el acceso a quien no tenga se tenga como contacto; $\mathrm{y}$ 
Linkedin organiza los perfiles de acuerdo a la ocupación profesional, lo que favorece el encuentro de personas que comparten una afinidad.

En la actualidad, el contacto no es concebible sin una red social; la cual se ha convertido en un elemento de integración social, de asociación y de relación entre iguales. Esto último es discutible considerando que las redes sociales, al no tener un control real, por la cantidad de usuarios que las utilizan, permiten la creación de perfiles falsos que son utilizados para agredir, denostar o acosar a una persona. A través de ellas se distribuyen fotos de carácter sexual sobre su persona; insultos, videos denigrantes, "memes" y difusión de rumores difamatorios (CAÑARTERODRÍGUEZ, 2017).

El ciberacoso es una forma de violencia que se ejerce con el uso del internet; afecta la vida privada y social de las víctimas, quienes reciben insultos, amenazas, intimidaciones, exclusiones de grupos de redes sociales; publicaciones falsas, vergonzosas e íntimas sobre la víctima, la cual no puede identificar al acosador debido a que se esconden en el anonimato, lo que dificulta su identificación

(INMUJERES, 2016)

La violencia hacia la mujer suele ser más ofensiva que hacia los varones: Karen González, originaria de Saltillo, Coahuila, denunció que era víctima de acoso en una red social; sin embargo, cuando alguien publicó una fotografía, presuntamente de ella con poca ropa, los comentarios fueron ofensivos y denigrantes, con los que se calificaba a la joven de mentirosa y en busca de cinco minutos de fama; por lo que prefirió cancelar su cuenta de Facebook (EXCELSIOR, 2017).

Otro ejemplo es el de Beatriz, de 49 años que se encontraba en su recamara con su hija Fernanda y al timbrar su celular, respondió a una video llamada, de una persona desconocida que del otro lado se tocaba sus partes íntimas y quien no sólo se limitó a masturbarse, sino que las amenazó con ir a su casa y violarlas: "yo se dónde viven y, como te tardaste viendo el video, sé que te gustó... y un día de estos, si tú me cuelgas yo voy a ir a tu casa, te encuentro a ti o encuentro a tu hija y te voy a violar..." (JORGE, 2018).

$\mathrm{Y}$ es que los Smartphones son los dispositivos digitales de mayor uso, 
el 64\% de la población usa WhatsApp y el 63\% Facebook. Las dos actividades principales en el uso del tiempo en línea es la navegación en redes sociales (79\%) y la mensajería instantánea (68\%). Las cámaras de estos equipos permiten hacer montajes o videos instantáneos, con contenido machista, sexista e incitaciones de odio y tener alcance a millones de usuarios, expuestos a la burla y a la humillación en grupos cerrados o de manera colectiva (BARRERA \& CANDY, 2017).

\section{Conclusión.}

La violencia contra la mujer tiene su origen en factores culturales como lo son el machismo y el feminismo que han imperado en el país. El patriarcado ha marcado las pautas que ambos géneros deben de seguir, principalmente asignándole a las mujeres las obligaciones de obediencia, respeto, lealtad y fidelidad; mientras que el machismo evita el empoderamiento de ellas y con ello se mantienen los cotos de poder para los varones, los cuales no están dispuestos a ceder su lugar a favor de las mujeres.

No en todas las legislaciones se contempla un castigo para el delito de acoso sexual, ya que generalmente se asocia con el hostigamiento sexual. En el Código Penal vigente en el Estado de Tabasco, impone una sanción de prisión de dos a cuatro años a quien asedie para sí o para un tercero a una persona con fines sexuales a pesar de su oposición manifiesta. Si una persona se vale de su posición jerárquica o derivada de relaciones laborales, docentes, domésticas o de cualquier otra que implique subordinación, la pena es de tres a seis años. Si trata de un servidor público, se le destituirá también de su cargo (DIPUTADOS, 2017).

Lo anterior significa un vacío en la ley, principalmente porque, el acoso y el hostigamiento, para que sean sexuales, requieren que haya un elemento lascivo; es decir, una relación sexual. En muchas ocasiones, las conductas desplegadas por los acosadores no manifiestan de manera directa sus intenciones, pero sí hacen patente a la víctima que ella tiene el derecho de elegir, cuando en realidad, se le está imponiendo un hacer sexual. En ese sentido, los acosadores tienen cuidado en no manifestar de manera directa sus intenciones, disfrazándolas de coqueteos o actitudes que permitan 
inferir su objetivo, pero sin hacerlo demasiado obvio, con la finalidad de evitar cualquier sanción.

El contexto de violencia estructural que impera en México señala que el $60 \%$ de mujeres mayores de 15 años (30.7 millones de mujeres) han sufrido de algún tipo de violencia en los diferentes ámbitos: escolar, laboral, comunitario, familiar o dentro de su relación de pareja (BARRERA \& CANDY, 2017) y no se puede descartar la violencia sexual relacionada con el acoso o el hostigamiento.

Lo preocupante en esta sociedad moderna es el clima de impunidad que rodea al acoso. Si a esto se agrega que las tecnologías de la información y la comunicación han tenido un desarrollo vertiginoso, entonces el derecho se ve rebasado ante el mundo de posibilidades que surgen; por ello, el ciberacoso ha obtenido la atención de todo el orbe pues se trata de una nueva forma de violencia que adquiere relevancia por la cantidad de casos que se denuncian.

No se debe de perder de vista que la violencia afecta el sano desarrollo de las mujeres y en su lucha ha logrado que se le reconozcan derechos como la

98

igualdad; aunque en materia de equidad se está lejos ya que todavía se confunden los órganos genitales con las funciones de cada género. Por ello, tanto el hostigamiento como el acoso son fenómenos que se presentan en la vida cotidiana del género femenino, el cual, al ir conociendo con mayor claridad sus derechos, aprende a ejercerlos denunciando los casos en los que se laceran sus derechos humanos; sin embargo, el nivel de impunidad aún es alto y por ello, es importante realizar una campaña de prevención partiendo desde el hogar y la escuela.

Con respecto al daño tanto físico como psicológico que sufre la víctima, es necesario brindarle la atención de manera pronta. Desafortunadamente, tanto el acoso como el hostigamiento se han naturalizado y las redes sociales han significado una prolongación de la comisión de algunos delitos. Es necesaria la realización de investigaciones con las que se busquen estrategias para frenar el fenómeno.

\section{Bibliografía}


AGUILAR, D., ARRIAGA, V., \& ET AL. (2017). El impacto del acoso sexual a hombres: el significado otorgado y su afrontamiento.

Alternativas psicológicas, 64-73.

ALZARD, D. (2013). Construcciones y estereotipos de feminidad reforzados a partir de la mitología clásica: el caso de Afrodita . Madrid: Facultad de Ciencias Económicas y Empresariales. Instituto de Investigaciones Feministas. Universidad Complutense de Madrid.

BARRERA, L., \& CANDY, R. (2017). La violencia en línea contra las mujeres en México. México: Luchadoras MX, Article 19 Oficina para México y Centroamérica, CIMAC.

CAÑARTE-RODRÍGUEZ， T. (2017). cyberbullying: el acoso a través de las redes sociales en jóvenes universitarios. Dominio de las Ciencias, 137-148.

CAZÉS, D. (1999). La perspectiva democrática del género. México: Consejo Nacional de Población (CoNaPo), Programa Nacional de la Mujer (ProNaM).
99

CENEPRED. (2005). Primera encuesta nacional sobre discriminación en México. México: Comsejo Nacional para Prevenir la Discriminación y Secretaría de Desarrollo Social.

CNDH. (2017). Acoso laboral "Mobbing". México: Comisión Nacional de los Derechos Humanos.

CNDH. (Julio de 2018). Contra el Bullying. Guía para docentes, alumnado, familias y cominidad escolar. Obtenido de Comisión Nacional de los Derechos Humanos: http://www.cndh.org.mx/sites/all/doc/pr ogramas/ninez_familia/material/cuadricontra-bullying.pdf

CoIDH. (16 de Noviembre de 2009). Caso González Y Otras ("Campo Algodonero") VS. México. Obtenido de Corte Interamericana de Derechos Humanos:

http://www.corteidh.or.cr/docs/casos/art iculos/seriec_205_esp.pdf

CONAPO. (2010). Informe de Ejecución del Programa de Acción de la Conferencia Internacional sobre la Población y el Desarrollo 1994-2009. México: Consejo Nacional de Población. 
Periódico do Núcleo de Estudos e Pesquisas sobre Gênero e Direito

Centro de Ciências Jurídicas - Universidade Federal da Paraíba V. 9 - $\mathrm{N}^{\circ} 01$ - Ano 2020 - Spanish Edition

ISSN | 2179-7137 | http://periodicos.ufpb.br/ojs2/index.php/ged/index
CONAVIM. (2016). Informe del Grupo de Trabajo conformado para atender la Solicitud de Alerta de Violencia de Género contra las Mujeres en el Estado de Tabasco. México: Comisión Nacional para Prevenir y Erradicar la Violencia Contra las Mujeres.

DIPUTADOS. (2017). Código Penal para el Estado de Tabasco. México: Coordinación General de Asuntos Jurídicos del Gobierno del Estado de Tabasco.

DIPUTADOS. (15 de 09 de 2019). Constitución Política de los Estados Unidos Mexicanos. México: Secretaria de Servicios Parlamentarios de la $\mathrm{H}$. Cámara de Diputados del H. Congreso de la Unión. Obtenido de Cámara de Diputados del H. Congreso de la Unión.

DOF. (01 de Febrero de 2007). Ley General de Acceso de las Mujeres a una vida libre de violencia. Obtenido de Secretaría de Gobernación. Diario Oficial dela Federación.: http://www.dof.gob.mx/nota_detalle.ph p? codigo $=4961209 \&$ fecha $=01 / 02 / 2007$
DOF. (31 de Agosto de 2016). Protocolo para la prevención, atención y sanción del hostigamiento sexual y acoso sexual. Obtenido de Secretaría de Gobernación. Diario Oficial dela Federación.: http://www.dof.gob.mx/nota_detalle.ph $\mathrm{p}$ ?codigo $=5450530 \&$ fecha $=31 / 08 / 2016$

DUARTE, J. M., \& BALTAZAR, G.-H. J. (2016). Igualdad, Equidad de género y Feminismo, una mirada histórica a la conquista de los derechos de las mujeres. CS, 18, 107-158.

EXCELSIOR. (24 de 05 de 2017). Es oficial, a los mexicanos les fascina Facebook. Obtenido de Excelsior: http://www.excelsior.com.mx/hacker/20 17/05/24/1165396

INMUJERES. (15 de 07 de 2016). Desigualdad en cifras. Obtenido de Gobierno de la República. Instituto Nacional de las Mujeres: http://cedoc.inmujeres.gob.mx/documen tos_download/BoletinN7_2016.pdf

JIMÉNEZ-BAUTISTA， F. (2012). Conocer para comprender la violencia: origen, causas y realidad. Convergencia, 13-52. 
trabajo y la masculinidad sexista I. San

JORGE, K. (14 de mayo de 2018). ¡Cuidado! Ciberacoso sexual por whatsapp. Obtenido de UNOTV: https://www.unotv.com/noticias/portal/i nvestigaciones-

especiales/detalle/cuidado-ciberacososexual-por-whatsapp-313648/

LAMAS, M. (1996). La perspectiva de género. Revista de Educación y Cultura de la Sección 47 del SNTE, 1-8.

MAGAÑA, L. D. (2014). El feminismo dentro de la representación de la mujer en la historia del arte: una mirada a los antecedentes de los diferentes estereotipos del cuerpo femenino dentro de la obra de arte. El Artista, 189-202.

OHCHR. (20 de diciembre de 1993). Declaración sobre la eliminación de la violencia contra la mujer. Obtenido de Oficina del Alto Comisionado de las Naciones Unidas de los Derechos Humanos:

https://www.ohchr.org/sp/professionalin terest/pages/violenceagainstwomen.asp $\mathrm{x}$

OIT. (2014). Guía para la intervencion con hombres sobre acoso sexual en el
José, Costa Rica: Organización Internacional del Trabajo.

OMS. (2013). Estimaciones mundiales y regionales de la violencia contra la mujer: prelavencia y efectos de la violencia conyugal y de la violencia sexual no conyugal en la salud. Obtenido de Organización Mundial de la Salid: https://apps.who.int/iris/bitstream/handl e/10665/85243/WHO_RHR_HRP_13.0 6_spa.pdf?sequence $=1$

OMS. (2019). Género. Obtenido de Organización Mundial de la Salud: https://www.who.int/topics/gender/es/

RAE. (2019). Acosar. Obtenido de Real Academia Española: https://dle.rae.es/?id=0ZpEHg5

REHERMANN, C. (2016). Cantos a la Dama Amor: Místicas y trovadoras de la Edad Media. CS 18, 107-158. Obtenido de Carlos Rehermann, artículos, ensayos y otros textos.

STPS. (S. F.). Trabajo de mujeres: cuestión de género. ¿Qué es el hostigamiento y el acoso sexual laboral? 
Obtenido

de

INMujeres:

http://cedoc.inmujeres.gob.mx/documen

tos_download/101096.pdf

UACJ. (S.F.). Curso Prevención y atención del acoso y hostigamiento sexual. México: Universidad Autónoma de Ciudad Juárez.

UNESCO. (1989). El manifiesto de Sevilla. Sevilla: Unidad Cultura de Paz de la UNESCO.

UNICEF. (S.F.). Aplicando género.

Obtenido de UNICEF Canadá: https://www.unicef.org/honduras/Aplica ndo_genero_agua_saneamiento.pdf 